\title{
2 Effects of soluble flavin on heterogeneous electron \\ cytochromes and iron oxides transfer between surface-exposed bacterial
} Zheming Wang,,$^{\dagger^{*}}$ Zhi Shi, Liang Shi,$^{\dagger}$ Gaye F. White, ${ }^{\dagger}$ David J. Richardson, ${ }^{\dagger}$ Thomas A.
Clarke, ${ }^{\dagger}$ Jim K. Fredrickson, ${ }^{\dagger}$ John M. Zachara ${ }^{\dagger *}$

(1)

(1)

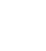

(0

\footnotetext{
†Pacific Northwest National Laboratory, PO Box 999, MS K8-96, Richland, WA 99352

Centre for Molecular and Structural Biochemistry, School of Biological Sciences and School of Chemistry, University of East Anglia, Norwich NR4 7TJ, United Kingdom
}

\footnotetext{
* Corresponding authors: Zheming Wang, Pacific Northwest National Laboratory, MS K8-96, Richland, WA 99354; Phone: (509) 371-6349; Fax: (509) 371-6354; E-mail: zheming.wang @ pnnl.gov; John M. Zachara, phone: 1509-371-6355, fax: 1-509-371-6354; Email: john.zachara@pnnl.gov.
} 
Dissimilatory iron-reducing bacteria can utilize insoluble $\mathrm{Fe}(\mathrm{Mn})$-oxides as a terminal electron acceptor under anaerobic conditions. For Shewanella species specifically, multiple evidences suggest that iron reduction is associated with the secretion of flavin mononucleotide (FMN) and riboflavin. However, the exact mechanism of flavin involvement is unclear; while some indicate that flavins mediate electron transfer (Marsili et al., 2008), others point to flavin serving as cofactors to outer membrane proteins (Okamoto et al., 2013). In this work, we used methyl viologen $\left(\mathrm{MV}^{\bullet+}\right)$-encapsulated, porin-cytochrome complex (MtrCAB) embedded liposomes

37 (MELs) as a synthetic model of the Shewanella outer membrane to investigate the proposed mediating behavior of microbially produced flavins. The reduction kinetics of goethite, hematite and lepidocrocite $(200 \mu \mathrm{M})$ by MELs $\left(\left[\mathrm{MV}^{\bullet+}\right] \sim 42 \mu \mathrm{M}\right.$ and MtrABC $\left.\leq 1 \mathrm{nM}\right)$ were determined in the presence FMN at $\mathrm{pH} 7.0$ in $\mathrm{N}_{2}$ atmosphere by monitoring the concentrations of $\mathrm{MV}^{\bullet+}$ and FMN through their characteristic UV-visible absorption spectra. Experiments were performed where i) FMN and Fe(III)-oxide were mixed and then reacted with the reduced MELs and ii) FMN was reacted with the reduced MELs followed by addition of Fe(III)-oxide. The redox reactions proceeded in two steps: a fast step that was completed in a few seconds, and a slower one lasting over 400 seconds. For all three Fe(III)-oxides, the initial reaction rate in the presence of a low concentration of FMN $(\leq 1 \mu \mathrm{M})$ was at least a factor of five faster than those with

47 MELs alone, and orders of magnitude faster than those by $\mathrm{FMNH}_{2}$, suggesting that FMN may serve as a co-factor that enhances electron transfer from outer-membrane $c$-cytochromes to

49 Fe(III)-oxides. The rate and extent of the initial reaction followed the order of lepidocrocite > hematite $>$ goethite, the same as their reduction potentials, implying thermodynamic control on

51 reaction rate. For LEP, with the highest reduction potential among the three Fe(III)-oxides, its

52 reduction by $\mathrm{FMNH}_{2}$ completed in less than 10 minutes, suggesting that FMN is capable of 
53 mediating electron transfer to LEP. At higher FMN concentrations $(>1 \mu \mathrm{M})$, the reaction rates

54 for both steps decreased and varied inversely with FMN concentration, indicating that FMN

55 inhibited the MEL to Fe(III)-oxide electron transfer reaction under these conditions. The

56 implications of the observed kinetic behaviors to flavin-mediated Fe(III) oxide reduction in

57 natural environments are discussed.

Dissimilatory iron reduction (DIR) by bacteria, which is linked to the reductive dissolution of

$\mathrm{Fe}(\mathrm{III})$ oxides is a key component of the iron biogeochemical cycle ((Lovley et al., 1987; Roden

61 and Zachara, 1996; Zachara et al., 2001)). At the heart of this process is extracellular and interfacial electron transfer between dissimilatory iron reducing bacteria (DIRB) and $\mathrm{Fe}(\mathrm{III})$ containing mineral phases that determines iron valence and solubility. A detailed understanding

64 of the mechanisms of dissimilatory iron reduction has arisen primarily from the study of two model organism species: Shewanella and Geobacter (Lovley, 1991; Myers and Nealson, 1988; Myers and Nealson, 1990). These organisms differ in the geochemical environments that they populate, electron donors utilized, molecular machinery for DIR, and other ecologic aspects. extracellular electron transfer (Clarke et al., 2011; Lies et al., 2005; Ross et al., 2009; Ross et al., 2007). Details of the Mtr pathway of MR-1 have been recently revealed (Clarke et al., 2011;

71 Hartshorne et al., 2009; Shi et al., 2007). Homologues of the Mtr pathway are present in

72 Geobacter (Liu et al., 2014) and Fe(II)-oxidizing bacteria (Shi et al., 2012b; Shi et al., 2012c),

73 attesting to the generality of its mechanism and function. The protein components of the Mtr

74 pathway of $S$. oneidensis MR-1 include multi-heme, $c$-type cytochromes (c-Cyts), CymA, $75 \operatorname{Mtr} A(D), M t r C(F)$ and OmcA; and a trans-membrane, porin-like protein $\mathrm{MtrB}(\mathrm{E})$ [Note MR-1 
has redundant gene clusters for the Mtr pathway giving rise to two distinct but closely similar protein series: MtrCAB and MtrFDE (Clarke et al., 2011) that form functional ternary molecular complexes (Richardson et al., 2012)]. CymA is a dehydrogenase that oxidizes quinol in the inner-membrane and transfers electrons to $\operatorname{MtrA}(\mathrm{D})$ either directly or indirectly via other periplasmic proteins. $M \operatorname{tr} A(D)$ inserts into porin protein $\operatorname{MtrB}(E)$ that spans the outer membrane. Outer membrane-bound $\operatorname{MtrC}(\mathrm{F})$ interact with $\mathrm{Mtr} A(\mathrm{D})$ to form a ternary complex that functions as a terminal reductase for electron transfer to Fe(III) solids (for recent reviews, see (Richardson et al., 2012; Shi et al., 2012a)).

Recent studies suggest that microbially produced soluble flavins can mediate electron transfer between the Mtr-pathway and Fe(III)-containing mineral phases. An electron shuttle mechanism is proposed (Brutinel and Gralnick, 2012). Within context of this study, an electron shuttle is defined as a relatively low molecular weight redox active molecule. Shuttles have favorable reaction properties for $\mathrm{Fe}(\mathrm{III})$ oxides and may diffuse into intra-aggregate or intragrain space not accessible to whole cells and have reaction kinetics that are not strongly constrained by the approach distance and orientation relative to outer membrane $c$-type cytochromes (Breuer et al., 2014; Brutinel and Gralnick, 2012). The shuttle hypothesis is based on circumstantial observations that (i) crystallized MtrF display a putative flavin-binding motif in their structure (Clarke et al., 2011), ii.) the Mtr pathway is required for extracellular reduction of flavins (Coursolle et al., 2010a; Coursolle et al., 2010b), (iii) purified MtrC and OmcA reduce flavins with subsequent electron transfer to Fe(III)(Ross et al., 2009; Shi et al., 2012c), (iv) higher flavin concentrations are associated with cell growth under anaerobic conditions where DIR occurs, and (v) addition of flavins to growth media enhance the reduction of poorly crystalline Fe(III) oxides (von Canstein et al., 2008; Wu et al., 2013). However, there has been 
no conclusive evidence to verify the mechanism by which flavin enhances $\mathrm{Fe}(\mathrm{III})$ oxide

100

101

102

103

104

105

106

107

108

109

110

111

112

113

114

115

116

117

118

119

120

121

reductive dissolution as its apparent effect could be associated with other undetermined factors

within the growth media. It is additionally unclear whether the mediating effect of flavin applies to all Fe(III)-oxides which vary in reduction potentials (Table 1) at more oxidizing values than those of flavins. The reduction rates of goethite by reduced flavin mononucleotide $\left(\mathrm{FMNH}_{2} ; \mathrm{E}\right.$ ' $\left.=-.216 \mathrm{~V} ; 0.001 \mu \mathrm{mol} \mathrm{m} \mathrm{m}^{-2} \mathrm{~s}^{-1}\right)$, for example, were three orders of magnitude slower than lepidocrocite $\left(1.1 \mu \mathrm{mol} \mathrm{m} \mathrm{m}^{-2}\right)($ Shi et al., 2012c; Shi et al., 2013). Thus, mediation efficiency may be dependent on the nature of Fe(III) oxides present in the geochemical system of interest.

We recently demonstrated a MtrCAB proteoliposome system for investigating interfacial electron transfer reactions between outer membrane cytochromes and mineral phases (White et al., 2012; White et al., 2013). The MtrCAB complex is embedded within the lipid bilayer with MtrC exposed on the outer surface of the liposome and MtrA on the inside, mimicking the in vivo organization of the MtrCAB electron transfer conduit between the periplasm and the outer membrane (Clarke et al., 2011; Ross et al., 2007; White et al., 2013). The methyl viologen cation $\left(\mathrm{MV}^{2+}\right)$, a redox-sensitive dye and strong reductant $\left(\mathrm{E}^{0}=-0.450 \mathrm{~V}\right)$, is encapsulated within the liposome to drive and monitor transmembrane electron transfer (Hartshorne et al., 2009; White et al., 2012). Encapsulated $\mathrm{MV}^{2+}$ is readily reduced to $\mathrm{MV}^{\bullet+}$ through the molecular conduit by stoichiometric addition of sodium dithionite outside of the proteoliposomes. The resulting $\mathrm{MV}^{\bullet+}$ containing proteoliposomes reduce both aqueous ferric complexes and suspended iron (III)

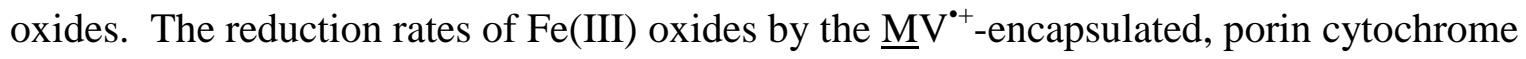

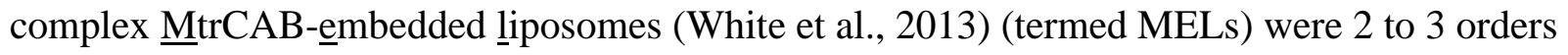
of magnitude faster than that by MtrC alone (Ross et al., 2009), albeit under different experimental conditions. 
In typical in vitro studies of $\mathrm{Fe}(\mathrm{III})$-oxide reductive dissolution by isolated outer-

123 membrane proteins or flavins, the reductant molecules are rapidly oxidized upon addition of

124 oxidant and the effective redox potential continuously increases as the reductant is oxidized

125 (Ross et al., 2009; Shi et al., 2012c; Shi et al., 2013; Wang et al., 2008). The MEL system with

126 encapsulated $\mathrm{MV}^{\bullet+}$, in contrast, provides a reservoir of reductant with relatively constant

127 reduction potential that is regulated by the redox properties of the outer-membrane proteins

128 (redox window of $-0.400-0.000 \mathrm{~V}$ (Hartshorne et al., 2009)) that span the lipid bilayer. The

129 outer membrane proteins, owing to their low concentration in the MEL suspension (e.g. 1 nM)

130 relative to $\mathrm{MV}^{\bullet+}(\sim 42 \mu \mathrm{M})$, experience a high redox turnover rate that simulates the in vivo

131 bacterial system that is driven by metabolism. Consequently, the MEL system represents an

132 experimental platform to evaluate select reaction mechanisms and kinetics of electron transfer

133 enhancement that is free from the complicating effects of alternative electron transfer pathways,

134 diffusive limitations to electron acceptor availability, other secreted organic molecules, growth,

135 and lysis that complicate whole cell studies.

Here we report on the reduction kinetics of goethite (GT), hematite (HT) and

137 lepidocrocite (LEP) by MELs in the presence of FMN under chemically constrained conditions

138 to evaluate the potential accelerating role of FMN in the extracellular reduction of Fe(III) oxides.

139 We examined the effects of FMN concentration and iron oxide phase identity, free energy (half-

140 cell potential), and concentration on the reductive dissolution rate. Evidence was explicitly

141 sought for reductive dissolution rate enhancement by FMN and the conditions under which this

142 occurred. The resulting experimental observations allowed us to refine a mechanistic

143 understanding of the impacts of microbially produced flavins on bacterial iron oxide reduction in

144 a complex model system. 


\section{EXPERIMENTAL}

\subsection{Materials and Methods}

Phosphatidylcholine, valinomycin, flavin mononucleotide (FMN), sodium dithionite

148 (sodium hydrosulfite, technical grade, 85\%), methyl viologen dichloride, ferrozine reagent (3-(2-

149 Pyridyl)-5,6-diphenyl-1,2,4-triazine-4',4''-disulfonic acid sodium salt), and HEPES, were

150 obtained from Sigma-Aldrich. Distilled, deionized water (DDW) with a resistivity of $18 \mathrm{M} \Omega-\mathrm{cm}$

151 (Barnstead Nanopure) was used for all experiments. Bottles and glassware were soaked in $2 \mathrm{M}$

152 hydrochloric acid (Sigma-Aldrich), rinsed with distilled water, soaked in $5 \mathrm{M}$ nitric acid (Fisher

153 Scientific), rinsed with distilled water, and then rinsed with DDW and air dried.

\subsection{Syntheses and characterization of Fe(III) oxides}

GT, HT, and LEP were synthesized according to the methods of Schwertmann and

Cornell (Schwertmann and Cornell, 2000). Details of the syntheses, washing, and the resulting material properties have been provided elsewhere (c; Shi et al., 2013). Reduction potential, surface area, and $\mathrm{pH}_{\mathrm{pzc}}$ values of the $\mathrm{Fe}(\mathrm{III})$-oxides are listed in Table 1.

\subsection{Preparation of MELs}

MELs with concentrations of $\mathrm{MV}^{2+} \sim 42 \mu \mathrm{M}$ and $\mathrm{MtrCAB}(\leq 1 \mathrm{nM})$ were prepared

162 were stored at $4{ }^{\circ} \mathrm{C}$ and used within two weeks after preparation.

\subsection{Experimental design and data analysis}

Batch experiments were conducted under conditions that were similar to those described

165 in White et al (White et al., 2012). In brief, all experiments were conducted in a glovebox (100\%

$166 \mathrm{~N}_{2}$ atmosphere, Innovative Technology, Inc., Amesbury, MA) with strict anaerobic conditions 
167 (oxygen concentration below the detection limit of $0.1 \mathrm{ppm}$ ) at $21.0 \pm 0.5^{\circ} \mathrm{C}$. Deoxygenated,

168 distilled, deionized water (DDDW) was prepared by boiling DDW in a 2 L bottle under vacuum

169 ( $450 \mathrm{~mm} \mathrm{Hg}$ vacuum) for 2 hour, and then sparging with high purity nitrogen gas overnight

170 inside the glovebox. The dissolved oxygen concentration in the DDDW was determined with a

171 colorimetric self-filling ampoule (CHEMetrics, Inc.), and the resulting analytical concentration

172 was always below the detection limit ( $5 \mathrm{ppb})$ of the colorimetric method. All samples were

173 prepared in $50 \mathrm{mM}$ HEPES buffer ( $\mathrm{pH}$ 7.0) containing $2 \mathrm{mM} \mathrm{CaCl}_{2}$ and $10 \mathrm{mM} \mathrm{KCl.} \mathrm{UV-}$

174 visible spectroscopy measurements were performed in $2.0 \mathrm{~mL}$ quartz cuvettes with continuous

175 stirring, and monitored by a Hewlett-Packard model 8543 diode array spectrometer.

176 The encapsulated methyl viologen radical cation $\left(\mathrm{MV}^{\bullet+}\right)$ functioned as the primary

177 reductant with electron transfer occurring through the MtrABC protein complex. Decrease of the

178 reduced methyl viologen cation $\left(\mathrm{MV}^{\bullet+}\right)$ concentration by oxidation to $\mathrm{MV}^{2+}$ was monitored at

$179606 \mathrm{~nm}$.

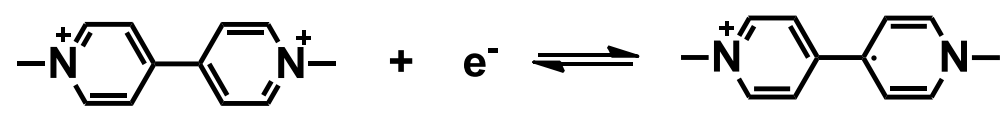

180

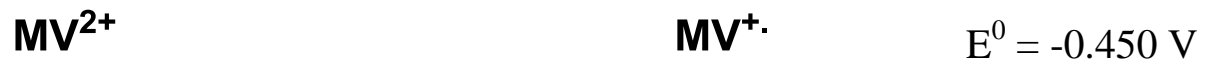

181 FMN was used as a secondary oxidant for $\mathrm{MV}^{\bullet+}$ (in addition to Fe(III) oxide), while its reduced

182 form, $\mathrm{FMNH}_{2}$, served as a secondary or parallel reductant for the Fe(III)-oxides. The

$183 \mathrm{FMN} / \mathrm{FMNH}_{2}$ redox pair has a similar but somewhat lower mid-point redox potential than the

184 Fe(III) oxides (Table 1). 


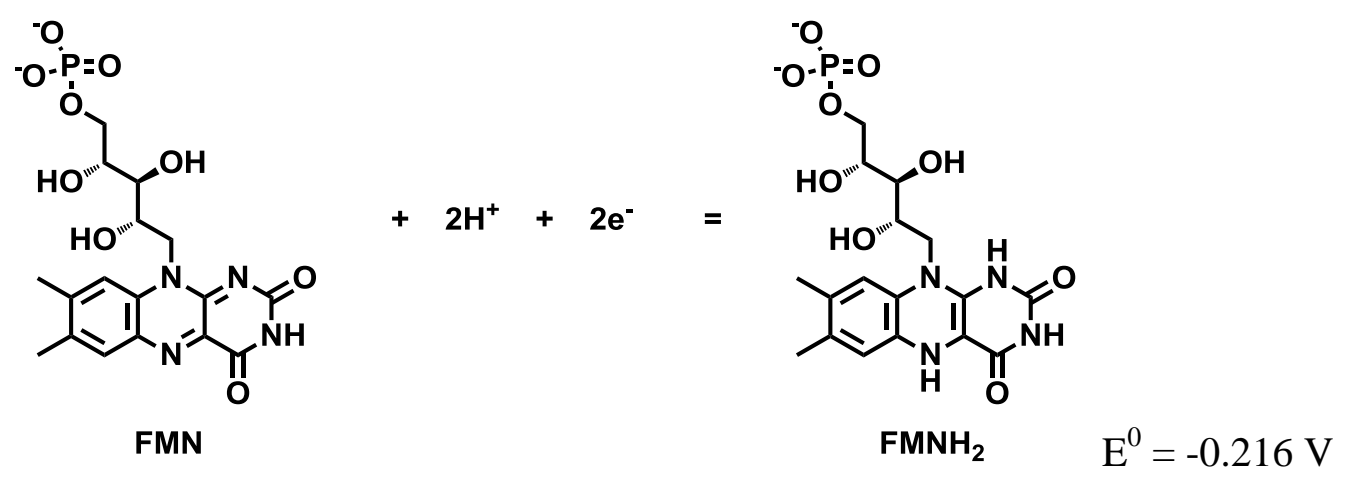

186 The change of FMN concentration was monitored at its characteristic absorption band at $450 \mathrm{~nm}$.

187 Absorbance data were converted to concentrations based on the extinction coefficients of $\mathrm{MV}^{\circ+}$, $188 \mathrm{FMN}, \mathrm{FMNH}_{2}$, and proteoliposomes at the corresponding wavelengths.

The initial concentration of $\mathrm{MV}^{\bullet+}$ in the MELs was determined by redox titration with 190 sodium dithionite of known concentration. Preliminary tests indicated that dithionite reduction 191 of $\mathrm{MV}^{2+}$ to $\mathrm{MV}^{*+}$ in the MELs reached completion within 20 min or less (White et al., 2012).

192 This reaction time was used for $\mathrm{MV}^{2+}$ reduction by sodium dithionite in all of the MEL 193 experiments, and the resulting reduced MEL suspensions were used for all the kinetic 194 experiments with FMN and/or Fe(III) oxides. Dithionite additions were carefully performed to 195 minimize post reaction residual concentrations, that could, in turn, have been reactive with the $196 \mathrm{Fe}(\mathrm{III})$ oxides and FMN. Consequently, the concentration of encapsulated $\mathrm{MV}^{\bullet+}$ in the working 197 solution was typically slightly less than the total MV concentration $\left(\left[\mathrm{MV}^{\bullet+}\right]+\left[\mathrm{MV}^{2+}\right]\right)$ as 198 measured after decomposition of the MELs $(42 \mu \mathrm{M})$ with Triton X-100 after completion of the 199 kinetic runs (White et al., 2013). were pre-mixed and quickly added to the MEL system to initiate reaction in the Type I 202 experiment, and the absorbances at $606 \mathrm{~nm}$ and $450 \mathrm{~nm}$ were monitored for 440 seconds. In the 
203 Type II experiment, FMN alone was added to the MEL suspension, and the reduction of FMN

204 was monitored for 220 seconds. Fe(III) oxide was then added to the suspension, and the reaction

205 was monitored for an additional 440 seconds. Variable concentrations of FMN were used for

206 both the Type $\mathrm{I}([\mathrm{FMN}]=0,1.0,10.0$ and $20 \mu \mathrm{M})$ and Type $\mathrm{II}([\mathrm{FMN}]=0.001,0.01,1.0,10.0$

207 and $20 \mu \mathrm{M}$ ) experiments with GT. For HT and LEP, Type I and Type II experiments were

208 conducted at $[\mathrm{FMN}]=10 \mu \mathrm{M}$ to allow comparison among the Fe-oxide phases. The resulting

$209 \mathrm{Fe}(\mathrm{II})$ concentration was determined by the ferrozine spectrophotometric method (Stookey,

210 1970). To minimize Fe(II) adsorption on the Fe(III)-oxide-MEL mixtures, ferrozine solution was

211 added to the reaction mixture prior to filtration and spectroscopy analysis.

The initial reaction rate, determined from the slope of the disappearance of the first $10 \%$

213 of the encapsulated $\mathrm{MV}^{\bullet+}$ (Shi et al., 2013; Stumm et al., 1985; Torrent et al., 1987; Wang and

214 Newman, 2008), and a second stage reaction rate, defined as the average rate from the inflection

215 point of the initial fast reaction and the slower reaction through 100 seconds, were calculated for

216 comparisons between the three Fe-oxides under different conditions. The 100 second data

217 window was selected to avoid potential measurement errors on the later reaction period for some

218 of the kinetic runs where $\mathrm{MV}^{*+}$ concentration within the MELs approached zero and the reaction

219 became extremely slow. The later period accounts for a small fraction of the overall reaction

220 extent. The kinetic data for the Type II experiments were also fitted to a second order reaction

221 model according to Wang et al. (Wang et al., 2008). The second order model was better suited

222 for kinetic analysis of the slower reaction stage. Details of the kinetic analysis approach have

223 been provided elsewhere (Wang et al., 2008). 
The simultaneous addition of FMN $(1,10$ or $20 \mu \mathrm{M})$ and GT $(200 \mu \mathrm{M})$ to the MEL

227 suspension led to the oxidation of the encapsulated $\mathrm{MV}^{\bullet+}$ to $\mathrm{MV}^{2+}$ within 420 seconds. The

228 electron transfer reactions proceeded in two stages at all three FMN concentration levels: a fast

229 initial stage that was completed within a few seconds and a slower one that took longer than 300

230 seconds. Separate measurements of the reduction of FMN in the absence of Fe(III) oxide

231 (Figures S2 and S3), or GT in the absence of FMN (Figure 1A) suggested that the fast reaction

232 involved the reduction of both FMN and GT while the slower reaction involved primarily GT.

233 Thus, soluble FMN $\left(\mathrm{E}^{0}=-0.216 \mathrm{~V}\right)$ reacted faster than nano-particulate $\mathrm{GT}\left(\mathrm{E}^{\prime}=-0.158 \mathrm{~V}\right)$ even

234 though the latter was thermodynamically more favorable (Table 1). Monitoring FMN absorbance

235 at $450 \mathrm{~nm}$ confirmed its rapid conversion to $\mathrm{FMNH}_{2}$ in the initial reaction stage in both the

236 presence and absence of GT. Thereafter, $\mathrm{FMNH}_{2}$ remained as the dominant flavin species during

237 the entire observation period (Figure 1B). $\mathrm{FMNH}_{2}$ did not appear to react with GT within the

238 experiment time frame, consistent with the slow rate of GT reduction by $\mathrm{FMNH}_{2}$ observed

239 under similar conditions in the absence of MELs $\left(0.001 \mu \mathrm{M} \mathrm{m}^{-2} \mathrm{~s}^{-1}\right)$ (Shi et al., 2013). The

240 production of $\mathrm{Fe}(\mathrm{II})$ decreased as FMN concentration increased (Figure 1C), indicating

241 preferential electron transfer to FMN rather than GT.

Inspection of the kinetic profiles (Figure 1A) and calculations of reactant/product stoichiometries revealed that FMN affected the reduction of GT differently during the two

244 reaction stages. In the initial stage, where the disappearance rate of $\mathrm{MV}^{\bullet+}$ was similar to the 245 reduction rate of FMN alone (Table 2), the drop in $\mathrm{MV}^{\bullet+}$ concentration was approximately 10 $246 \mu \mathrm{M}$ more than the stoichiometric demand from the production of $\mathrm{FMNH}_{2}$ when $1 \mu \mathrm{M}$ and $10 \mu \mathrm{M}$ 247 FMN were present in the suspension (Figure 1A). The additional oxidation of $\mathrm{MV}^{\bullet+}$ could only 248 be attributed to the reduction of GT at greatly enhanced rate. This observation was consistent 
with the hypothesis that FMN serves as a co-factor for the reduction of $\mathrm{Fe}(\mathrm{III})$-oxides by

Shewanella outer-membrane $c$-Cyts (Okamoto et al., 2013) (No molecular mechanism implied). However, in the second stage, the presence of $\mathrm{FMNH}_{2}$ inhibited the reduction of GT. The second stage GT reduction rates decreased from $0.33 \mu \mathrm{M} \mathrm{s}^{-1}$ in the absence of $\mathrm{FMNH}_{2}$ to 0.16 $\mu \mathrm{M} \mathrm{s}^{-1}$ and $0.01 \mu \mathrm{M} \mathrm{s}^{-1}$ in the presence $1 \mu \mathrm{M}$ and $10 \mu \mathrm{MFMNH}_{2}$, respectively (Table S1). As a significant portion of GT reduction occurred during the second stage, the overall effect of FMN was to inhibit GT reduction (Figure 1C).

\subsection{Type II experiments with goethite}

FMN solutions of varying concentration $(0,2 \mathrm{nM}, 10 \mathrm{nM}, 1 \mu \mathrm{M}, 10 \mu \mathrm{M}$ and $20 \mu \mathrm{M})$ were first reacted with the MELs to completion (e.g., $\mathrm{FMNH}_{2}$ ) in the Type II experiment. GT was then added to the suspension and its reduction kinetics determined by UV-vis monitoring. Thus, the measured kinetic profiles only involved GT reduction, allowing determination of GT reduction rate without the complication of the concurring fast reduction of FMN. In all cases, the reduction of FMN by the MELs prior to Fe(III) oxide addition was almost instantaneous except with $20 \mu \mathrm{M}$ FMN, for which a slower stage, similar to that observed in Type I experiment at the same FMN concentration (Figure 1A), was observed (Figures S2 and S3). The addition of $2 \mathrm{nM}$ or $10 \mathrm{nM}$ FMN resulted in initial GT reduction rates $\left(3.29 \mu \mathrm{M} \mathrm{s}^{-1}\right.$ and $3.39 \mu \mathrm{M} \mathrm{s}^{-1}$, respectively) that were over five times greater than those without FMN $\left(0.59 \mu \mathrm{M} \mathrm{s}^{-1}\right)$. However, the overall effect of these low FMN concentrations on the kinetic profiles of $\mathrm{MV}^{\bullet+}$ oxidation (as compared to $[\mathrm{FMN}]=0$ ) was limited (Figure $2 \mathrm{~A}$ and Table 2).

An increase of FMN to $1 \mu \mathrm{M}$ led to further enhancement of the initial rate to $8.74 \mu \mathrm{M} \mathrm{s}^{-1}$ (Table 2), while decreasing the second stage reaction rate from $\sim 0.33 \mu \mathrm{M} \mathrm{s}^{-1}$ (without FMN) to $0.17 \mu \mathrm{M} \mathrm{s}^{-1}$ (Table S1). An additional increase in FMN to $10 \mu \mathrm{M}$ led to a further decrease in the 
272 second stage rate (to $0.04 \mu \mathrm{M} \mathrm{s}^{-1}$, Table S1), and lowering of the initial reaction rate to $3.20 \mu \mathrm{M}$

$273 \mathrm{~s}^{-1}$ (Table 2). At all four FMN concentrations, the measured initial rates were at least five times

274 greater than that in the absence of FMN (Table 2). Because FMN was in the reduced form

$275\left(\mathrm{FMNH}_{2}\right)$ prior to GT introduction, the oxidation of $\mathrm{MV}^{\circ+}$ in Figures $2 \mathrm{~A}$ and $2 \mathrm{~B}$ only involved

276 electron transfer to GT. The rapid $\mathrm{MV}^{\bullet+}$ oxidation during the initial reaction with $2 \mathrm{nM}$ to 10

$277 \mu \mathrm{M} \mathrm{FMNH}_{2}$ (most evident for 1 and $10 \mu \mathrm{M}$ Figure $2 \mathrm{~B}$ ) provided unequivocal evidence that

$278 \mathrm{FMNH}_{2}$ interacted with the MtrCAB complex to allow more efficient electron transfer to GT.

279 The reduction of $20 \mu \mathrm{M}$ FMN prior to goethite addition consumed all the $\mathrm{MV}^{\bullet+}$, and thus no

280 further $\mathrm{MV}^{\bullet+}$ reaction with GT was observed at this high $\mathrm{FMNH}_{2}$ concentration (Figure 2B).

281 The small amount of $\mathrm{Fe}^{2+}{ }_{(\mathrm{aq})}$ observed in the $20 \mu \mathrm{M} \mathrm{FMNH} 2$ experiment $(\sim 3 \mu \mathrm{M}$, Figure $2 \mathrm{C})$

282 was believed to result from residual dithionite. At all FMN concentration levels, the measured

283 concentration of FMN during the reaction with GT remained at zero (data not shown), indicating

284 little reaction of GT with $\mathrm{FMNH}_{2}$.

A consecutive second-order bimolecular model was applied to simulate the kinetic data given the negligible reaction between $\mathrm{FMNH}_{2}$ and GT (typical data fits are shown in Figure S4).

287 The results revealed that the reduction of GT displayed a single stage bimolecular kinetic

288 reaction with a rate constant of $\sim 89 \mu \mathrm{M}^{-1} \cdot \mathrm{s}^{-1}$ in the absence of $\mathrm{FMNH}_{2}$. In the presence of

289 reduced $\mathrm{FMNH}_{2}$, all experiments could be modeled by a two-stage bimolecular process with rate 290 constants dependent on the concentration of $\mathrm{FMNH}_{2}$ (Table S2). The rate constants of the initial 291 stage were all over three times higher than those in the absence of $\mathrm{FMNH}_{2}$; they increased with 292 FMN concentration to $\left[\mathrm{FMNH}_{2}\right]=1 \mu \mathrm{M}$, and then decreased at higher $\mathrm{FMNH}_{2}$ concentration.

293 The slower reaction peaked at $10 \mathrm{nM} \mathrm{FMNH}_{2}$ and decreased monotonically as $\mathrm{FMNH}_{2}$

294 concentration increased. These data trends were consistent with those determined by the initial 
295 (Table 2) and second stage reaction rate analysis (Table S1), supporting the conclusions that

$\left.296 \mathrm{FMNH}_{2} \mathrm{i}\right)$ enhanced the initial reaction rate at low concentrations $\left(\left[\mathrm{FMNH}_{2}\right] \leq 1 \mu \mathrm{M}\right)$, and ii)

297 impeded the second stage reaction at $\left[\mathrm{FMNH}_{2}\right] \geq 1 \mu \mathrm{M}$.

A comparison of the kinetic data obtained in the Type I and II experiments indicated that the sequence of reactant addition affected the kinetic behavior of the reactions with GT. The initial $\mathrm{MV}^{\circ+}$ oxidation rates were much higher in Type I experiment than those in Type II experiment at the same FMN concentration $(10 \mu \mathrm{M})$ because of rapid, FMN reduction. On the other hand, the reaction rates in the Type II experiment were descriptive of the fundamental kinetic interaction between the $\mathrm{FMNH}_{2}$-modified MEL reductants and GT.

\subsection{Reductive dissolution of hematite and lepidocrocite in MELs suspensions}

Type I and Type II experiments were performed using HT and LEP under the same conditions used for GT with FMN at $10 \mu \mathrm{M}$. Control experiments in the absence of FMN demonstrated that the reduction rates by MELs followed the order of GT $<$ HT $<$ LEP (Figures 2A, 3A and 4A; Table 2) as reported previously (White et al., 2013).

3.3.1 Type I Experiments The reaction of HT and LEP displayed similar patterns to that of GT, with an initial rapid drop of $\mathrm{MV}^{+\bullet}$ concentration from $\sim 40 \mu \mathrm{M}$ to $\sim 11 \mu \mathrm{M}$, followed by

311 a reaction stage that was slower than that in the absence of FMN (Figures 3A and 4A). For GT, 312 there was a lag period between the initial and slower stages of reactions (Figure 1A). The lag 313 period was much shorter for HT and non-existent for LEP, likely caused by the greater thermodynamic driving force for the latter reaction pairs. The initial rates were all fast due to the

315 dominance of fast FMN reduction by MELs during this period (Table 2) while the second stage 316 reaction rates were smaller than those in the absence of FMN (Table S1). Among the three 
317 Fe(III)-oxides, the second stage rates increased from GT $\left(0.01 \mu \mathrm{M} \mathrm{s}^{-1}\right)$ to HT $\left(0.05 \mu \mathrm{M} \mathrm{s}^{-1}\right)$ to $318 \operatorname{LEP}\left(0.12 \mu \mathrm{M} \mathrm{s}^{-1}\right)$.

Pronounced differences were observed in the FMN concentration profiles over the course 320 of the reaction for HT and LEP as compared to GT (Figs. 1B, 3B and 4B). While FMN was 321 quickly reduced and remained as $\mathrm{FMNH}_{2}$ during reaction with GT, [FMN] dropped to $\sim 3 \mu \mathrm{M}$

322 during the initial reaction in the mixture with HT with the remaining FMN reduced slowly 323 (Figure 3B). In the reaction with LEP, the concentration of FMN displayed a momentary 324 concentration dip to $\sim 4.2 \mu \mathrm{M}$ at the beginning of the reaction, followed by an immediate 325 rebound to nearly the starting FMN concentration; only a marginal additional decrease was 326 observed during the remainder of the reaction period (Figure 4B). The concentration rebound of 327 FMN suggested $\mathrm{FMNH}_{2}$ oxidation by reaction with LEP. This result was consistent with rapid 328 measured rates of $\mathrm{FMNH}_{2}$ reaction with LEP in the absence of MELs $\left(r_{\text {initial }}=1.3 \mu \mathrm{M} \mathrm{s}^{-1}\right)($ Shi et 329 al., 2012c).

331 GT and HT (Figures $1 \mathrm{C}$ and 3D), confirming that HT reduction by $\mathrm{FMNH}_{2}$ was minimal over 332 the experimental period. Thus, an equivalent concentration of $\mathrm{MV}^{+\bullet}(\leq 22 \mu \mathrm{M})$ was available for 333 reaction with GT and HT yielding an equivalent Fe(II) $)_{\mathrm{aq}}$ concentration. For LEP, the measured $334\left[\mathrm{Fe}(\mathrm{II})_{\mathrm{aq}}\right]$ was the same as the starting concentration of $\mathrm{MV}^{+\bullet} ; \mathrm{MV}^{+\bullet}$ reduced LEP quantitatively 335 (Figure 4D). LEP reduction in the presence of FMN apparently involved both direct reaction 336 with electron conduit MtrABC, and secondary reaction with $\mathrm{FMNH}_{2}$. 
339 followed the same trend observed for GT, except with higher initial rates and, in case of LEP, a

340 much larger extent of reduction (Figures 3A, 4A and Table 2). The oxidation of $\sim 90 \%$ of the

$341 \mathrm{MV}^{+\bullet}$ occurred within a few seconds in the MELs-FMNH $2-\mathrm{LEP}_{2}$ suspension (Figure 4A). In

342 comparison, over 100 seconds was necessary to reach the same reaction extent under similar

343 conditions using MELs or $\mathrm{FMNH}_{2}$ alone (Figure 4A and Figure 1 in ref. (Shi et al., 2012c)).

344 Such rate enhancement was consistent with the observations made for the MELs $+\mathrm{GT}+\mathrm{FMNH}_{2}$

345 system, and further confirmed that $\mathrm{FMNH}_{2}$ enhanced MtrCAB electron transfer to Fe(III)-

346 oxides.

In contrast to its rate enhancing effect on the initial reaction, the presence of $\mathrm{FMNH}_{2}$

348 reduced the second stage reaction rates by factors of four and fifteen for HT and LEP,

349 respectively, as compared to rates in the absence of FMN (Table S1). Similar trends were

350 observed in the second-order bimolecular rate constants (Table S2).

The concentration profiles of FMN (Fig. 3C) and the evolved Fe(II) concentration (Fig.

352 3D) showed little evidence for $\mathrm{FMNH}_{2}$ reaction with HT. In contrast, LEP reduction in the Type

353 II experiment was coupled to $\mathrm{FMNH}_{2}$ oxidation (Figure 4C) which occurred rapidly between 5

354 and 100 seconds after $\mathrm{MV}^{+\bullet}$ was exhausted by LEP reduction. All of the $\mathrm{FMNH}_{2}(10 \mu \mathrm{M})$ was

355 oxidized by the completion of the experiment (440 seconds), albeit at decreasing rate (Fig. 4C).

356 In the end, $[\mathrm{Fe}(\mathrm{II})]$ was close to the initial $\mathrm{MV}^{+\bullet}$ concentration $(\leq 42 \mu \mathrm{M})$ (Figure 4D), indicating

357 that all electron equivalents originally present in $\mathrm{MV}^{+\bullet}$ were transferred to LEP through a

358 combination of direct reaction with $\mathrm{MtrCAB}$ and parallel reaction with $\mathrm{FMNH}_{2}$. This was not

359 the case for either the GT or HT systems.

\section{DISCUSSION}




\subsection{Thermodynamic and kinetic relationships}

Nernst equation calculations indicated that $\mathrm{MV}^{\bullet+}$ oxidation by FMN and all three Fe(III)-

363

oxides should be quantitative under the experimental conditions used. Similar calculations predicted that the oxidation of $\mathrm{FMNH}_{2}$ by the $\mathrm{Fe}$ (III)-oxides should also be close to $100 \%$ (Table S3). Consistent with these calculations, the oxidation of $\mathrm{MV}^{\circ+}$ in the MELs system was complete within $~ 400$ seconds for all systems studied (Figures 1-4). However, the stoichiometric reduction of Fe(III)-oxides by $\mathrm{FMNH}_{2}$, once formed, was only observed for LEP (Table 2) because of kinetic constraints. The concentration of Fe(II) for both GT and HT was below thermodynamic expectation given measured concentrations of $\mathrm{FMNH}_{2}$. Calculations with previously reported initial rates of $\mathrm{Fe}(\mathrm{III})$ oxide reductive dissolution by $\mathrm{FMNH}_{2}$ (Shi et al., 2013) suggested that only $3.2 \mu \mathrm{M}$ and $0.4 \mu \mathrm{M}$ Fe(II) should be produced in 400 seconds for the reaction with HT and GT, respectively, while the reaction with LEP would be complete. The production of $\mathrm{Fe}(\mathrm{II})_{(\mathrm{aq})}$ from the reaction of $\mathrm{FMNH}_{2}$ with GT or HT was less than the calculated values in our experiments because only a portion of the reactions proceeded at the initial rate, and there was less $\mathrm{FMNH}_{2}$ in the present system (typically $\leq 10 \mu \mathrm{M}$ ) than used for the initial rate measurement (Shi et al., 2013). Consequently, $\mathrm{FMNH}_{2}$, which was rapidly produced from FMN by the MELs, functioned as an electron sink in the GT and HT systems because of its relatively slow kinetic reactivity with these two more stable Fe(III) oxides. As will be discussed below, the thermodynamic driving force is more favorable for reaction between $\mathrm{FMNH}_{2}$ and LEP.

Generally, a larger redox reaction free energy (i.e., greater difference between the effective reduction potentials of oxidant and reductant) for similar reactants leads to a faster reaction rate (e.g. Shi et al., 2013). We have previously shown that the initial surface area normalized reduction rate of $\mathrm{Fe}(\mathrm{III})$-oxide by $\mathrm{FMNH}_{2}$ increased with increases in the reduction 
384 potential of the Fe(III)-oxide phase $\left(0.001 \mu \mathrm{mol} \cdot \mathrm{m}^{-2} \cdot \mathrm{s}^{-1}\right.$ for GT, $0.008 \mu \mathrm{mol} \cdot \mathrm{m}^{-2} \cdot \mathrm{s}^{-1}$ for HT, and $3851.1 \mu \mathrm{mol} \cdot \mathrm{m}^{-2} \cdot \mathrm{s}^{-1}$ for LEP) (Shi et al., 2012c; Shi et al., 2013). For Fe(III)-oxide reduction by 386 aqueous $\mathrm{MV}^{\bullet+}$, the surface area normalized reduction rate increased from $1.36 \mu \mathrm{mol} \cdot \mathrm{m}^{-2} \cdot \mathrm{s}^{-1}$ for 387 GT, to $2.63 \mu \mathrm{mol} \cdot \mathrm{m}^{-2} \cdot \mathrm{s}^{-1}$ for HT, and to $6.1 \mu \mathrm{mol} \cdot \mathrm{m}^{-2} \cdot \mathrm{s}^{-1}$ for LEP (White et al., 2013). These 388 data also showed that the higher reduction potential of $\mathrm{FMNH}_{2}(-0.216 \mathrm{~V})$ compared to that of $389 \mathrm{MV}^{\bullet+}(-0.450 \mathrm{~V})$ led to significantly lower initial reduction rates of a given Fe(III)-oxide by $390 \mathrm{FMNH}_{2}$ as compared by $\mathrm{MV}^{\bullet+}$ at the same $\mathrm{Fe}(\mathrm{III})$-oxide concentration. The initial surface area 391 normalized rates for the Type II experiments presented herein where Fe(III)-oxides reacted with $392 \leq 22 \mu \mathrm{M}$ of encapsulated $\mathrm{MV}^{\bullet+}$ and $10 \mu \mathrm{MFMNH}_{2}$, followed the same order as expected from 393 the reduction potentials $\left(4.73 \mu \mathrm{mol} \cdot \mathrm{m}^{-2} \cdot \mathrm{s}^{-1}\right.$ for $\mathrm{GT}<11.10 \mu \mathrm{mol} \cdot \mathrm{m}^{-2} \cdot \mathrm{s}^{-1}$ for $\mathrm{HT}<11.21 \mu \mathrm{mol} \cdot \mathrm{m}^{-}$ $394^{2} \cdot \mathrm{s}^{-1}$ for LEP; Table 2). Therefore, thermodynamic driving force is a key factor in our 395 experimental system, with the differences between $\mathrm{MV}^{\bullet+}$ and $\mathrm{FMNH}_{2}$ being especially important 396 in determining the kinetic competence of $\mathrm{FMNH}_{2}$ to act as a parallel reductant to $\mathrm{MV}^{\circ+} / \mathrm{MtrCAB}$ 397 However, the thermodynamic driving force of $\mathrm{MV}^{\circ+}$ is propagated through the MtrCAB complex 398 which is limited in concentration $(\leq 1 \mathrm{nM})$ and gated by intra- and inter-proteins heme 399 arrangement to function over a specified redox window (e.g., $\sim 0.400 \mathrm{~V}$ to $0.000 \mathrm{~V}$ ). Due to the 400 large concentration differences between the encapsulated $\mathrm{MV}^{\circ+}$ and the MtrCAB complex 401 embedded on the liposome surface, the effective reduction potential (E') of the MELs are 402 expected to be near the lowest reduction potential of the MtrCAB complex (i.e. -0.400 403 V;(Hartshorne et al., 2009)).

A single MR-1 cell has been estimated to contain approximately $1.2 \times 10^{-19}$ moles of the 405 MtrCAB complex (Ross et al., 2009). Thus, a typical Shewanella culture with $10^{10}$ cells/L may 406 contain $1.2 \mathrm{nM}$ MtrCAB, which is similar to the MtrCAB concentration in our MEL system. 
Our model system consequently mimics select features of the Mtr pathway, with similar concentrations of the electron transfer complex MtrCAB as found in MR-1 cultures. However, the periplasmic reduction potential of Shewanella is driven by the redox couple $\mathrm{NAD}^{+} / \mathrm{NADH}$ with a mid-point potential of $-0.320 \mathrm{~V}$ (White et al., 2013) at sustainable $\mu \mathrm{M}-$ level concentrations (Wimpenny and Firth, 1972). The significantly lower reduction potential of $\mathrm{MV}^{\bullet+}$

412 as compared to NADH along with an initial reductant concentration (e.g., $\sim 42 \mu \mathrm{M}$ ) that was

413 higher than the cytoplasmic electron pool provided a large thermodynamic driving force for

414 reduction (of both FMN and Fe(III)-oxides) in our system relative to whole cells. The resulting $415 \mathrm{Fe}(\mathrm{III})$-oxide reduction rates for the MELs were consequently higher than observed for whole 416 cells or in-vitro studies with isolated $c$-Cyts or (Coursolle et al., 2010; Lies et al., 2005; von

417 Canstein et al., 2008) because of thermodynamic, reactant concentration, and other effects.

\subsection{Reaction pathways}

Our results suggest that $\mathrm{FMNH}_{2}$ may play multiple roles in the reduction of $\mathrm{Fe}(\mathrm{III})$ oxides by the Mtr pathway. The overall kinetic behavior of the MELs + FMN + Fe(III) oxide

421 system is interpreted to result from four fundamental kinetic reactions that occur at different rates 422 (Figure 5). FMN reacts rapidly with $\mathrm{MV}^{\bullet+}$ through the $\mathrm{MtrCAB}$ complex to form $\mathrm{FMNH}_{2}$ and 423 activated complex MtrABC-(FMN) in Reaction 1. This step transfers a portion of the electron 424 equivalents from $\mathrm{MV}^{\bullet+}$ to FMN. In Reaction 2, a portion of the remaining electron equivalents 425 from $\mathrm{MV}^{*+}$ are transferred to $\mathrm{Fe}(\mathrm{III})$ oxide through the activated MtrCAB-(FMN) complex at an 426 enhanced rate relative to the reaction between MELs and Fe-oxide (Reaction 3), which proceeds 427 in parallel. Stored electron equivalents in $\mathrm{FMNH}_{2}$ are the last to react with the $\mathrm{Fe}(\mathrm{III})$ oxides in 428 Reaction 4, where significant reaction progress was noted only for LEP because of 429 thermodynamic constraints. Reaction of $\mathrm{FMNH}_{2}$ with GT and HT would have been observed 
430 after significantly longer time periods. Differences between the kinetic behaviors of the three

431 oxides in the ternary system can be rationalized by the noted range in the four reaction rates (Fig.

432 5). Several aspects of these reaction sequences warrant additional discussion.

A significant observation was that $\mathrm{FMNH}_{2}$ at low concentration $(\leq 1 \mu \mathrm{M})$ accelerates the

434 initial electron transfer rate to all three Fe(III) oxides studied by a factor of five or more over that

435 in the absence of $\mathrm{FMNH}_{2}$ (Table 2). The initial reduction rates for all three phases followed the

436 order of MELs $+\mathrm{FMNH}_{2(\mathrm{aq})}>\mathrm{MV}^{\bullet+}{ }_{(\mathrm{aq})}>\mathrm{MELs}>>\mathrm{FMNH}_{2}$ (Figure 6). Our interpretation of

437 this results is that a molecular interaction between FMN (or its reduced species FMNH', or

$\left.438 \mathrm{FMNH}_{2}\right)$ and $\mathrm{MtrCAB}$ [e.g. (FMN) in Fig. 5] leads to rate enhancement. Crystal structure

439 determinations for MtrF, a homologue of MtrC, suggested the presence of two flavin binding

440 domains (per MtrF molecule) near the heme core that could be involved in such interaction

441 (Clarke et al., 2011). A specific, but as yet unidentified species of FMN may consequently serve

442 as a co-factor for MtrC as suggested by Okamoto et al (Okamoto et al., 2013) during the initial

443 stage of $\mathrm{Fe}(\mathrm{III})$-oxide reductive dissolution. It is currently unclear what factors control the

444 overall extent of electron transfer through the activated complex [e.g. moles of Fe(II) produced

445 through Reaction 2].

Saturation of the flavin binding domain is anticipated at low $\mathrm{FMNH}_{2}$ concentrations

447 given the nano-molar concentration of MtrCAB in the MELs and the existence of only two FMN

448 binding domains on each MtrCAB complex (Clarke et al., 2011). Domain saturation is

449 consistent with the observed trend that no further enhancement in initial rate was observed at

$450\left[\mathrm{FMNH}_{2}\right] \geq 1 \mu \mathrm{M}$. Measured extracellular flavin concentrations in anaerobic cell culture

451 medium of Shewanella are typically in the sub-micromolar range (Ross et al., 2009; von

452 Canstein et al., 2008), indicating that only low flavin concentrations are necessary for 
453 enhancement of reductive dissolution rates by whole cells. Enhanced reaction rates have been

454 observed for other co-factors, such as $\mathrm{Mn}$ (II) and $\mathrm{Ni}$ (II) for bacterial protein phosphatases (Shi et 455 al., 2001).

FMN concentrations in excess of one micromolar inhibited Fe(III)-oxide reduction during

457 the second, slower reaction stage. FMN exerted brief, yet significant initial rate enhancement at 2 $458 \mathrm{nM}$ and $10 \mathrm{nM}$ (Figure 2A, B). After that, the reaction kinetics were almost identical to those in 459 the absence of FMN, except for a concentration decrease in $\mathrm{MV}^{\bullet+}$ that corresponded to the 460 amount reacted during the initial stage. Beginning at $[\mathrm{FMN}]=1 \mu \mathrm{M}$, where the initial reaction 461 rate peaked, the second stage became slower as compared to that in the absence of $\mathrm{FMNH}_{2}$, and 462 inhibition become more pronounced as the $\mathrm{FMNH}_{2}$ concentration was increased. The inhibition 463 effect was common to all three Fe(III)-oxides based on data at $10 \mu \mathrm{M} \mathrm{FMNH}_{2}$ (Figures 2-4 and 464 Table S1).

One possible explanation for the observed inhibition effect was $\mathrm{FMNH}_{2}$ adsorption on 466 Fe(III)-oxide. Flavins strongly adsorb to Fe/Mn-oxides, carbon electrodes, gold nanoparticles, 467 and bacteria cell surfaces (Marsili et al., 2008; Shi et al., 2012c). Assuming a molecular 468 diameter of $1.3 \mathrm{~nm}$ for $\mathrm{FMNH}_{2}$, we estimated that a monolayer of $\mathrm{FMNH}_{2}$ on goethite might 469 contain $2.1 \times 10^{17} \mathrm{FMNH}_{2}$ molecules (the equivalent of $3.3 \times 10^{-7} \mathrm{M} \mathrm{FMNH}_{2}$ ), which is within the 470 range of concentrations studied here. The formation of a surface complex between phosphate 471 groups on $\mathrm{FMN}$ or $\mathrm{FMNH}_{2}$ and surface $\mathrm{Fe}(\mathrm{III})$ is plausible (Mortland et al., 1984) and might 472 restrict access of exposed MtrC to the Fe(III)-oxide through steric and/or electrostatic 473 interaction.

\section{CONCLUSIONS AND IMPLICATIONS}


The present study revealed that microbially produced FMN may play multiple roles in the

476

477

478

479

480

481

482

483

484

485

486

487

488

489

490

491

492

493

494

495

496

497

microbial reduction of $\mathrm{Fe}(\mathrm{III})$-oxides. These roles include function as: 1) a co-factor to $\mathrm{MtrC}$

enhancing its electron transfer (to all Fe(III) oxides), 2) a parallel reductant serving as an electron

shuttle to the Mtr pathway (lepidocrocite only), and 3) an "unreactive" electron sink over the experimental time period (goethite and hematite). The latter two roles were determined and constrained by the aqueous reductive dissolution rates of $\mathrm{FMNH}_{2}$ with the individual $\mathrm{Fe}(\mathrm{III})$ oxides. Through possible specific interaction between $\mathrm{MtrCAB}$ and $\mathrm{FMN} / \mathrm{FMNH}_{2}, \mathrm{FMNH}_{2}$ enhanced electron transfer rates between the MELs and Fe(III)-oxides by a factor of 3.4, 4.2 and 1.8 for GT, HT and LEP, respectively, compared to that by aqueous $\mathrm{MV}^{\bullet+}$. Such enhancement was optimized at sub-micromolar FMN concentrations, a level commonly observed in whole cell cultures under anaerobic conditions.

Many natural systems contain ferrihydrite as the predominant $\mathrm{Fe}(\mathrm{III})$ oxide. It is a nanocrystalline phase (Jambor and Dutrizac, 1998) that is a stronger oxidant than lepidocrocite.

Ferrihydrite is rapidly dissolved by FMN (Shi et al., 2012c). It was not studied here because of its strong tendency to recrystallize to more stable Fe(III) oxide phases (goethite and lepidocrocite) in presence of Fe(II) (Yee et al., 2006; Zachara et al., 2011). We suspect that ferrihydrite reduction would be greatly enhanced over that observed for lepidocrocite by the parallel reactions of MELs and reduced flavin (e.g. $\mathrm{FMNH}_{2}$ ).

The behavior of the MtrCAB/FMN/Fe(III) oxide system was strongly dependent on 1) the physiologic redox potential that poises the MtrCAB complex, and 2) the half-cell potential of the $\mathrm{Fe}(\mathrm{III})$ oxide phase that regulates the relative reaction rates with redox-poised $c$-Cyt and FMN. The concentration ratios of reductants $\left(\mathrm{MEL}-\mathrm{MV}^{\bullet+}\right)$ to oxidants [Fe(III) oxide], and the concentration of the electron transfer conduit (MtrABC) were also important. These same 
498 dependencies are expected for whole cell and natural systems, with additional complexities

499 increasing with observational scale. For FMN-enhanced Fe(III)-oxide reduction by MELs, the

500 surface normalized initial rates at $10 \mu \mathrm{M}$ FMN varied within a factor of three between goethite

$501 \quad\left(4.73 \mu \mathrm{mol} \mathrm{m} \mathrm{m}^{-2}\right)$, hematite $\left(11.10 \mu \mathrm{mol} \mathrm{m} \mathrm{m}^{-2} \mathrm{~s}^{-1}\right)$, and lepidocrocite $\left(11.21 \mu \mathrm{mol} \mathrm{m}^{-2} \mathrm{~s}^{-1}\right)$. Yet,

502 for $\mathrm{Fe}(\mathrm{III})$-oxide reduction by $\mathrm{FMNH}_{2}$, the same rates varied over three orders of magnitude

503 from $\sim 0.001 \mu \mathrm{mol} \mathrm{m} \mathrm{s}^{-1}$ for goethite to $1.1 \mu \mathrm{mol} \mathrm{m} \mathrm{m}^{-1}$ for lepidocrocite. Additional research

504 is required to determine whether these striking differences are thermodynamically or

505 mechanistically controlled, and how these findings relate to natural systems.

506 Liposomes encapsulating reductants with redox potentials near that of NADH are now

507 being tested to constrain model system studies to a physiologically relevant redox window.

508 Outer membrane vesicles (Schooling and Beverage, 2006; Kim et al., 2007; Pirbadian et al.,

509 2014) are also being considered with redox properties closer to in vivo conditions. Through the

510 use of physiologically relevant reductants and membrane systems, additional insights on the

511 kinetic mechanisms of Fe(III)-oxide reduction by DIRB can be gained.

512 SUPPORTING INFORMATION. Four figures and three tables.

513

514 ACKNOWLEDGMENTS

515 This research was supported by the Geoscience Research Program of the Office of Basic Energy

516 Science (BES), U.S. Department of Energy (DOE). The contribution of Jim Fredrickson and

517 Liang Shi were supported by Pacific Northwest National Laboratory Scientific Focus Area

518 (PNNL SFA). Part of this research was performed at EMSL, a national scientific user facility at

519 PNNL managed by the Department of Energy’s Office of Biological and Environmental 
520 Research. Pacific Northwest National Laboratory is operated for the U.S. Department of Energy

521 by Battelle under Contract DE-AC06-76RLO 1830. 
Table 1. Relevant properties of Fe-oxides in this work $^{\mathrm{a}}$.

\begin{tabular}{|c|c|c|c|c|c|}
\hline \multirow[t]{2}{*}{ Iron oxides } & \multirow{2}{*}{$\begin{array}{c}\text { One-electron reduction half reaction } \\
\text { (relevant } \Delta \mathrm{G}_{\mathrm{f}}^{\mathrm{o}} \text { and } \Delta \mathrm{G}^{\mathrm{o}} \text { values are provided under } \\
\text { each species) }\end{array}$} & \multicolumn{2}{|c|}{$\begin{array}{l}\text { Redox potentials } \\
\qquad(\mathrm{mV})\end{array}$} & \multirow{2}{*}{$\begin{array}{l}\text { BET } \\
\text { surface } \\
\text { area } \\
\left(\mathrm{m}^{2} \cdot \mathrm{g}^{-1}\right)\end{array}$} & \multirow[t]{2}{*}{$\mathrm{pH}_{\mathrm{zpc}}{ }^{\mathrm{c}}$} \\
\hline & & $\mathrm{E}^{\mathrm{o}}$ & $E^{\prime}$ & & \\
\hline Goethite & $\alpha-\mathrm{FeOOH}(\mathrm{s})+3 \mathrm{H}^{+}+\mathrm{e}^{-}=\mathrm{Fe}^{2+}+2 \mathrm{H}_{2} \mathrm{O}$ & 727 & -158 & 38 & $7.5-9.5$ \\
\hline Hematite & $\alpha-\mathrm{Fe}_{2} \mathrm{O}_{3}(\mathrm{~s})+6 \mathrm{H}^{+}+2 \mathrm{e}^{-}=2 \mathrm{Fe}^{2+}+3 \mathrm{H}_{2} \mathrm{O}$ & 764 & -121 & 34 & $7.5-9.5$ \\
\hline Lepidocrocite & $\gamma-\mathrm{FeOOH}(\mathrm{s})+3 \mathrm{H}^{+}+\mathrm{e}^{-}=\mathrm{Fe}^{2+}+2 \mathrm{H}_{2} \mathrm{O}$ & 781 & -104 & 130 & $6.7-7.5$ \\
\hline
\end{tabular}

${ }^{a}$ See Zhi et al (Shi et al., 2012c; Shi et al., 2013) for the basis of the thermodynamic values and morphological characterization results. ${ }^{\mathrm{b}}$ Calculated using $\mathrm{E}^{\mathrm{o}}=-\Delta \mathrm{G}^{\mathrm{o}} / \mathrm{nF}$, and Nernst equation. Faraday constant $\mathrm{F}=96.485 \mathrm{~kJ}$ per volt gram equivalent. $\mathrm{E}^{\prime}$ : $\mathrm{pH} 7.0$, $1 \mu \mathrm{M}$ total dissolved iron. ${ }^{\mathrm{c}}$ From (Cornell and Schwertmann, 2003), page 235. 
Table 2. Initial reaction rates of Fe-oxide reduction by $\mathrm{MV}^{+\bullet}$-encapsulated proteoliposomes in Type I and Type II reaction schemes at various initial flavin mononucleotide (FMN) concentrations at $25^{\circ} \mathrm{C}$. $200 \mu \mathrm{M}$ Fe(III) oxide, $40 \mu \mathrm{M} \mathrm{MV}^{+\bullet}, 50 \mathrm{mM}$ HEPES buffer (pH 7.0) containing $2 \mathrm{mM} \mathrm{CaCl} 2$ and $10 \mathrm{mM} \mathrm{KCl}$. Fe(III) oxides include goethite (GT), hematite (HT) and lepidocrocite (LEP).

\begin{tabular}{|c|c|c|c|c|}
\hline Mineral & $\begin{array}{c}{[\mathrm{FMN}]} \\
(\mu \mathrm{M})\end{array}$ & $\begin{array}{l}\text { Initial } \\
\text { rate } \\
\left(\mu \mathrm{M} \cdot \mathrm{s}^{-1}\right)\end{array}$ & $\begin{array}{c}\text { Surface area } \\
\text { normalized initial } \\
\text { rate } \\
\left(\mu \mathrm{mol} \cdot \mathrm{m}^{-2} \cdot \mathrm{s}^{-1}\right)\end{array}$ & $\begin{array}{l}\text { Steady state } \\
{\left[\mathrm{Fe}_{\mathrm{aq}}^{\mathrm{II}}\right]} \\
(\mu \mathrm{M})^{\mathrm{a}, \mathrm{b}}\end{array}$ \\
\hline \multicolumn{5}{|c|}{ Type I Experiment } \\
\hline None & 10.0 & $54.33 \pm 3.73$ & - & - \\
\hline \multirow[t]{4}{*}{ GT } & 0.0 & $0.59 \pm 0.07$ & $0.88 \pm 0.10$ & $35.3 \pm 1.0(40.0)$ \\
\hline & 1.0 & $10.28 \pm 2.82^{c}$ & $15.23 \pm 4.18$ & $32.8 \pm 1.7(38.0)$ \\
\hline & 10.0 & $56.83 \pm 25.67$ & $84.19 \pm 38.03$ & $13.4 \pm 0.4(20.0)$ \\
\hline & 20.0 & $53.51 \pm 23.64$ & $79.27 \pm 35.02$ & $2.0 \pm 0.1(0.0)$ \\
\hline \multirow[t]{2}{*}{ HT } & 0.0 & $0.97 \pm 0.11$ & $1.78 \pm 0.21$ & $37.1 \pm 0.3(40.0)$ \\
\hline & 10.0 & $42.90 \pm 3.29^{c}$ & $63.56 \pm 4.87$ & $15.4 \pm 1.1(20.0)$ \\
\hline \multirow[t]{2}{*}{ LEP } & 0 & $5.43 \pm 1.39$ & $2.35 \pm 0.60$ & $37.0 \pm 3.7(40.0)$ \\
\hline & 10.0 & $77.51 \pm 5.58^{\mathrm{c}}$ & $33.56 \pm 2.42$ & $41.0 \pm 1.2(20.0)$ \\
\hline \multicolumn{5}{|c|}{ Type II Experiment } \\
\hline \multirow[t]{5}{*}{ GT } & 0.002 & $3.29 \pm 0.70$ & $4.87 \pm 1.04$ & $33.3 \pm 1.1(40.0)$ \\
\hline & 0.01 & $3.39 \pm 1.15$ & $5.02 \pm 1.71$ & $33.1 \pm 3.0(40.0)$ \\
\hline & 1.0 & $8.74 \pm 0.79$ & $12.95 \pm 1.17$ & $30.0 \pm 2.8(38.0)$ \\
\hline & 10.0 & $3.20 \pm 0.54$ & $4.73 \pm 0.79$ & $15.2 \pm 3.3(20.0)$ \\
\hline & 20.0 & - & - & $2.6 \pm 0.6(0.0)$ \\
\hline HT & 10.0 & $6.03 \pm 0.32$ & $11.10 \pm 0.58$ & $14.0 \pm 0.2(20.0)$ \\
\hline LEP & 10.0 & $25.90 \pm 5.93$ & $11.21 \pm 2.57$ & $38.8 \pm 0.9(20.0)$ \\
\hline
\end{tabular}

$532{ }^{a}$ value in parenthesis is the expected value based on reactant stoichiometries.

$533{ }^{\mathrm{b}}$ Calculated using $\mathrm{E}^{\mathrm{o}}$ (hematite) $=764 \mathrm{mV}$ (Shi et al., 2013).

$534{ }^{\mathrm{c}}$ Initial rates in these Type I experiments are dominated by FMN reduction by MELs. 


\section{REFERENCES}

Breuer, M., Rosso, K. M., and Blumberger, J. (2014) Electron flow in multiheme bacterial cytochromes is a balancing act between heme electronic interaction and redox potentials. Proc. Natl. Acad. Sci. USA 111, 611-616.

Brutinel, E. D. and Gralnick, J. A. (2012) Shuttling happens: soluble flavin mediators of extracellular electron transfer in Shewanella. Appl. Microbiol. Biot. 93, 41-48.

Clarke, T. A., Edwards, M. J., Gates, A. J., Hall, A., White, G. F., Bradley, J., Reardon, C. L., Shi, L., Beliaev, A. S., Marshall, M. J., Wang, Z., Watmough, N. J., Fredrickson, J. K., Zachara, J. M., Butt, J. N., and Richardson, D. J. (2011) Structure of a bacterial cell surface decaheme electron conduit. Proc. Natl. Acad. Sci. USA 108, 9384-9389.

Cornell, R. M. and Schwertmann, U. (2003) The Iron Oxides: Structure, Properties, Reactions, Occurrences, and Uses. Wiley, Weinheim.

Coursolle, D., Baron, D. B., Bond, D. R., and Gralnick, J. A. (2010a) The Mtr respiratory pathway is essential for reducing flavins and electrodes in Shewanella oneidensis. $J$ Bacteriol 192, 467-474.

Hartshorne, R. S., Reardon, C. L., Ross, D., Nuester, J., Clarke, T. A., Gates, A. J., Mills, P. C., Fredrickson, J. K., Zachara, J. M., Shi, L., Beliaev, A. S., Marshall, M. J., Tien, M., Brantley, S., Butt, J. N., and Richardson, D. J. (2009a). Characterization of an electron conduit between bacteria and the extracellular environment. Proc. Natl. Acad. Sci. USA 106, 22169-22174.

Jambor, J. L. and Dutrizac, J. E. (1998) Occurrence and constitution of natural and synthetic ferrihydrite, a widespread iron oxyhydroxide. Chemical Reviews 98, 2549-2585.

Kim, J.-Y., Doody, A.M., Chen, D.J., Cremona, G.H., Shuler, M.L., Putnam, D., and DeLisa, M.P. (2008) Engineered Bacterial Outer Membrane Vesicles with Enhanced Functionality. J. Mol. Biol. 380, 51-66.

Lies, D. P., Hernandez, M. E., Kappler, A., Mielke, R. E., Gralnick, J. A., and Newman, D. K. (2005) Shewanella oneidensis MR-1 uses overlapping pathways for iron reduction at a distance and by direct contact under conditions relevant for biofilms. Appl. Environ. Microbiol. 71, 4414-4426.

Liu, Y., Wang, Z., Liu, J., Levar, C., Edwards, M., Babauta, J. T., Kennedy, D. W., Shi, Z., Beyenal, H., Bond, D. R., Clarke, T. A., Butt, J. N., Richardson, D. J., Rosso, K. M., Zachara, J. M., Fredrickson, J. K., and Shi, L. (2014) A trans-outer membrane porincytochrome protein complex for extracellular electron transfer by Geobacter sulfurreducens PCA. Environ. Microbiol. Rep. (doi: 10.1111/1758-2229.12204).

Lovley, D. R. (1991) Dissimilatory Fe(III) and Mn(IV) reduction. Microbiol. Rev. 55, 259-287.

Lovley, D. R., Stolz, J. F., Nord, G. L., and Phillips, E. J. P. (1987) Anaerobic production of magnetite by a dissimilatory iron-reducing microorganism. Nature 330, 252-254.

Marsili, E., Baron, D. B., Shikhare, I. D., Coursolle, D., Gralnick, J. A., and Bond, D. R. (2008) Shewanella Secretes flavins that mediate extracellular electron transfer. Proc. Natl. Acad. Sci. USA 105, 3968-3973.

Mortland, M. M., Lawless, J. G., Hartman, H., and Frankel, R. (1984) Smectite interactions with flavomononucleotid. Clays Clay Miner. 32, 279-282.

Myers, C. R. and Nealson, K. H. (1988) Bacterial manganese reduction and growth with manganese oxide as the sole electron-acceptor. Science 240, 1319-1321. 
Myers, C. R. and Nealson, K. H. (1990) Respiration-linked proton translocation coupled to anaerobic reduction of manganese(IV) and iron(III) in shewanella-putrefaciens MR-1. $J$. Bacteriol. 172, 6232-6238.

Okamoto, A., Hashimoto, K., Nealson, K. H., and Nakamura, R. (2013) Rate enhancement of bacterial extracellular electron transport involves bound flavin semiquinones. Proc. Natl. Acad. Sci. USA 110, 7856-7861.

Pirbadian, S., Barchinger, S.E., Leung, K.M., Byun, H.S., Jangir, Y., Bouhenni, R.A., Reed, S.B., Romine, M.F., Saffarini, D.A., Shi, L., Gorby, Y.A., Golbeck, J.H., and El-Naggar, M.Y. (2014) Shewanella Oneidensis Mr-1 Nanowires Are Outer Membrane and Periplasmic Extensions of the Extracellular Electron Transport Components. Proc. Natl. Acad. Sci. USA 111, 12883-12888.

Richardson, D. J., Butt, J. N., Fredrickson, J. K., Zachara, J. M., Shi, L., Edwards, M. J., White, G., Baiden, N., Gates, A. J., Marritt, S. J., and Clarke, T. A. (2012) The porincytochrome' model for microbe-to-mineral electron transfer. Mol. Microbiol. 85, 201212.

Roden, E. E. and Zachara, J. M. (1996) Microbial reduction of crystalline iron(III) oxides: Influence of oxide surface area and potential for cell growth. Environ. Sci. Technol. 30, 1618-1628.

Ross, D. E., Brantley, S. L., and Tien, M. (2009) Kinetic Characterization of OmcA and MtrC, Terminal Reductases Involved in Respiratory Electron Transfer for Dissimilatory Iron Reduction in Shewanella oneidensis MR-1. Appl. Environ. Microbiol. 75, 5218-5226.

Ross, D. E., Ruebush, S. S., Brantley, S. L., Hartshorne, R. S., Clarke, T. A., Richardson, D. J., and Tien, M. (2007) Characterization of protein-protein interactions involved in iron reduction by Shewanella oneidensis MR-1. Appl. Environ. Microbiol. 73, 5797-5808.

Schwertmann, U. and Cornell, R. M. (2000) Iron oxides in the laboratory preparation and characterization. Wiley-VCH, Wiley-VCH.

Schooling, S.R. and Beveridge, T.J. (2006) Membrane Vesicles: An Overlooked Component of the Matrices of Biofilms. J. Bacteriol. 188, 5945-5957.

Shi, L., Kehres, D. G., and Maguire, M. E. (2001) The PPP-family protein phosphatases PrpA and PrpB of Salmonella entetica serovar typhimurium possess distinct biochemical properties. J. Bacteriol. 183, 7053-7057.

Shi, L., Rosso, K. M., Clarke, T. A., Richardson, D. J., Zachara, J. M., and Fredrickson, J. K. (2012a) Molecular underpinnings of Fe(III) oxide reduction by Shewanella oneidensis MR-1. Frontiers in Microbiology 3. Article 50:1-10.

Shi, L., Rosso, K. M., Zachara, J. M., and Fredrickson, J. K. (2012b) Mtr extracellular electrontransfer pathways in $\mathrm{Fe}$ (III)-reducing or $\mathrm{Fe}$ (II)-oxidizing bacteria: a genomic perspective. Biochem Soc Trans 40, 1261-7.

Shi, L., Squier, T. C., Zachara, J. M., and Fredrickson, J. K. (2007) Respiration of metal (hydr)oxides by Shewanella and Geobacter: a key role for multihaem $c$-type cytochromes. Mol. Microbiol. 65, 12-20.

Shi, Z., Zachara, J. M., Shi, L., Wang, Z., Moore, D. A., Kennedy, D. W., and Fredrickson, J. K. (2012c) Redox Reactions of Reduced Flavin Mononucleotide (FMN), Riboflavin (RBF), and Anthraquinone-2,6-disulfonate (AQDS) with Ferrihydrite and Lepidocrocite. Environ. Sci. Technol. 46, 11644-11652.

Shi, Z., Zachara, J. M., Wang, Z., Shi, L., and Fredrickson, J. K. (2013) Reductive dissolution of goethite and hematite by reduced flavins. Geochim. Cosmochim. Acta 121, 139-154. 
Stookey, L. L. (1970) Ferrozine - A new spectrophotometric reagent for iron. Anal. Chem. $\mathbf{4 2}$, 779-781.

Stumm, W., Furrer, G., Wieland, E., and Zinder, B. (1985) The effects of complex-forming ligands on the dissolution of oxides and aluminosilicates. In: Drever, J. I. (Ed.),The Chemistry of Weathering. D. Reidel, Dordrecht, The Netherlands.

Torrent, J., Schwertmann, U., and Barron, V. (1987) The reductive dissolution of synthetic goethite and hematite in dithionite. Clay Miner. 22, 329-337.

von Canstein, H., Ogawa, J., Shimizu, S., and Lloyd, J. R. (2008) Secretion of flavins by Shewanella species and their role in extracellular electron transfer. Appl. Environ. Microbiol. 74, 615-623.

Wang, Y. and Newman, D. K. (2008) Redox reactions of phenazine antibiotics with ferric (hydr)oxides and molecular oxygen. Environ. Sci. Technol. 42, 2380-2386.

Wang, Z. M., Liu, C. X., Wang, X. L., Marshall, M. J., Zachara, J. M., Rosso, K. M., Dupuis, M., Fredrickson, J. K., Heald, S., and Shi, L. (2008b) Kinetics of Reduction of Fe(III) Complexes by Outer Membrane Cytochromes MtrC and OmcA of Shewanella oneidensis MR-1. Appl. Environ. Microbiol. 74, 6746-6755.

White, G. F., Shi, Z., Shi, L., Dohnalkova, A. C., Fredrickson, J. K., Zachara, J. M., Butt, J. N., Richardson, D. J., and Clarke, T. A. (2012) Development of a proteoliposome model to probe transmembrane electron-transfer reactions. Biochem. Soc. Trans. 40, 1257-1260.

White, G. F., Shi, Z., Shi, L., Wang, Z., Dohnalkova, A. C., Marshall, M. J., Fredrickson, J. K., Zachara, J. M., Butt, J. N., Richardson, D. J., and Clarke, T. A. (2013) Rapid electron exchange between surface-exposed bacterial cytochromes and Fe(III) minerals. Proc. Natl. Acad. Sci. USA 110, 6346-51.

Wimpenny, J. W. and Firth, A. (1972) Levels of nicotinamide adenine dinucleotide and reduced nicotinamide adenine dinucleotide in facultative bacteria and the effect of oxygen. $J$. Bacteriol. 111, 24-32.

Wu, C., Cheng, Y.-Y., Li, B.-B., Li, W.-W., Li, D.-B., and Yu, H.-Q. (2013) Electron acceptor dependence of electron shuttle secretion and extracellular electron transfer by Shewanella oneidensis MR-1. Bioresource Technol. 136, 711-714.

Yee, N., Shaw, S., Benning, L. G., and Nguyen, T. H. (2006) The rate of ferrihydrite transformation to goethite via the Fe(II) pathway. American Mineralogist 91, 92-96.

Zachara, J. M., Fredrickson, J. K., Smith, S. C., and Gassman, P. L. (2001) Solubilization of $\mathrm{Fe}$ (III) oxide-bound trace metals by a dissimilatory Fe(III) reducing bacterium. Geochim. Cosmochim. Acta 65, 75-93.

Zachara, J. M., Kukkadapu, R. K., Peretyazhko, T., Bowden, M., Wang, C., Kennedy, D. W., Moore, D., and Arey, B. (2011) The mineralogic transformation of ferrihydrite induced by heterogeneous reaction with bioreduced anthraquinone disulfonate (AQDS) and the role of phosphate. Geochim. Cosmochim. Acta 75, 6330-6349. 


\section{Figure captions}

Figure 1. Kinetic data of GT reduction by MELs in the absence or presence of FMN at different concentrations in the Type I experiment. Reaction conditions: $40 \mu \mathrm{M} \mathrm{MV}^{+\cdot}, 200 \mu \mathrm{M}$ GT, 50 mM HEPES buffer (pH 7.0). FMN concentrations: 0, 1, 10, and $20 \mu \mathrm{M}$. (A) $\mathrm{MV}^{+\cdot}$ concentration as a function of time; (B) FMN concentration as a function of time with $10 \mu \mathrm{M}$ initial FMN; (C) aqueous $\mathrm{Fe}^{2+}$ concentration measured at the end of kinetic experiment.

Figure 2. Kinetic data of GT reduction by MELs in the absence or presence of FMN at different concentrations, Type II experiment. Reaction conditions: 35 - $40 \mu \mathrm{M} \mathrm{MV}^{+\cdot}, 200 \mu \mathrm{M} \mathrm{GT}, 50 \mathrm{mM}$ HEPES buffer (pH 7.0). FMN concentrations: 0, 0.002, 0.01, 1, 10, and $20 \mu \mathrm{M}$. (A) and (B) $\mathrm{MV}^{+\cdot}$ concentration as a function of time after Fe(III) oxide addition, only show the step 2; (C) aqueous $\mathrm{Fe}^{2+}$ concentration measured at the end of kinetic experiment. The red arrow labeled $\mathrm{t}_{2,0}$ points to the start time of the Type II reaction with GT.

Figure 3. Kinetic data of HT reduction by MELs in the absence or presence of $10 \mu \mathrm{M} F M N$ in Type I and Type II experiments. Reaction conditions: 35 - $40 \mu \mathrm{M} \mathrm{MV}^{+}, 200 \mu \mathrm{M}$ HT, $50 \mathrm{mM}$ HEPES buffer ( $\mathrm{pH} 7.0$ ). (A) $\mathrm{MV}^{+\cdot}$ concentration as a function of time. The red arrow labeled $\mathrm{t}_{2,0}$ points to the start time of the type II reaction with HT. No FMN was added in control run; (B) FMN concentration as a function of time in Type I experiment; (C) FMN concentration as a function of time in Type II experiment at the second step; (D) aqueous $\mathrm{Fe}^{2+}$ concentration measured at the end of kinetic experiment.

Figure 4. Kinetic data of LEP reduction by MELs in the absence or presence of $10 \mu \mathrm{M} \mathrm{FMN} \mathrm{in}$ Type I and Type II experiment. Reaction conditions: 35 - $40 \mu \mathrm{M} \mathrm{MV}^{+}, 200 \mu \mathrm{M}$ LEP, $50 \mathrm{mM}$ HEPES buffer ( $\mathrm{pH} 7.0$ ). (A) $\mathrm{MV}^{+\cdot}$ concentration as a function of time. The red arrow labeled $\mathrm{t}_{2,0}$ points to the start time of the Type II reaction with LEP. No FMN was added in control run. (B) FMN concentration as a function of time in Type I experiment; (C) FMN concentration as a function of time in Type II experiment at the second step; (D) aqueous $\mathrm{Fe}^{2+}$ concentration measured at the end of kinetic experiment.

Figure 5. Schematic representations of the reaction pathways for Fe(III)-oxide reduction by MELs in the presence of $\mathrm{FMNH}_{2}$. $(\mathrm{FMN})=$ cytochrome bound FMN. The overall kinetic behavior of the MELs + FMN + Fe(III) oxide system is the result of four fundamental kinetic reactions that occur at different rates: A) FMN reacts with MELs resulting $\mathrm{FMNH}_{2}$ and MtrCAB-bound activated complex, MtrCAB-(FMN); B) Electron transfer via the MtrCAB(FMN) leads to very fast reduction of Fe-oxide by MELs; C) In parallel, MELs reduce Fe(III)oxide at intermediate to fast rates; and D) Fe-oxide reduction by $\mathrm{FMNH}_{2}$ at slow to intermediate rate dictated by the thermodynamic driving forces.

Figure 6. Comparisons of the surface-normalized initial rates of Fe-oxide reductive dissolution by $\mathrm{MV}^{*+}$ encapsulated in proteoliposomes in the presence of $10 \mu \mathrm{M} \mathrm{FMNH}_{2}$ (Type II experiment) in the present work with those by aqueous $\mathrm{MV}^{\circ+}$, , aqueous $\mathrm{FMNH}_{2}{ }^{\mathrm{b}}$ and $\mathrm{MV}^{\circ+}$ encapsulated in proteoliposomes without $\mathrm{FMNH}_{2}{ }^{\mathrm{a}}$ at $\mathrm{pH}$ 7.0. ${ }^{\mathrm{a}}$ Data from (White et al., 2013); Data from (Shi et al., 2012c; Shi et al., 2013). 

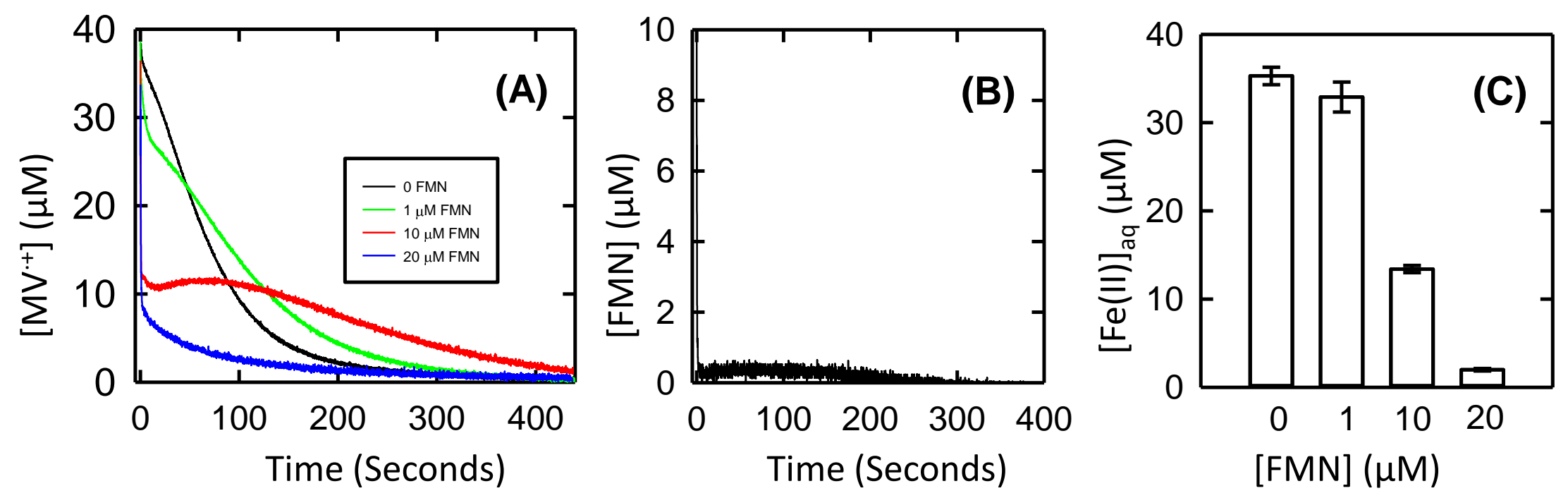

Wang et al Figure 1 

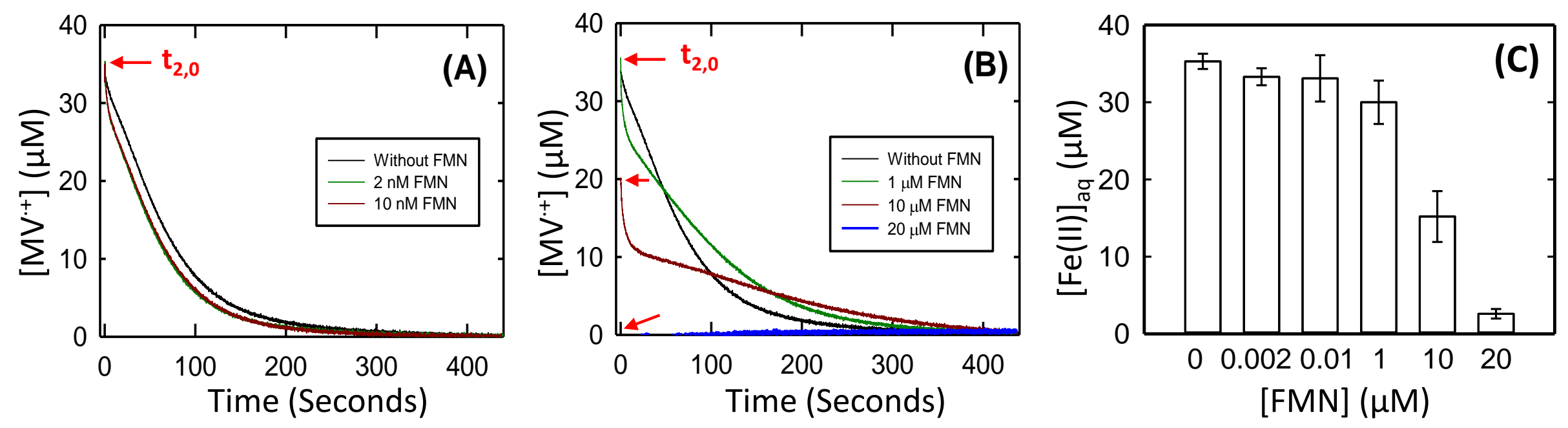

Wang et al Figure 2 

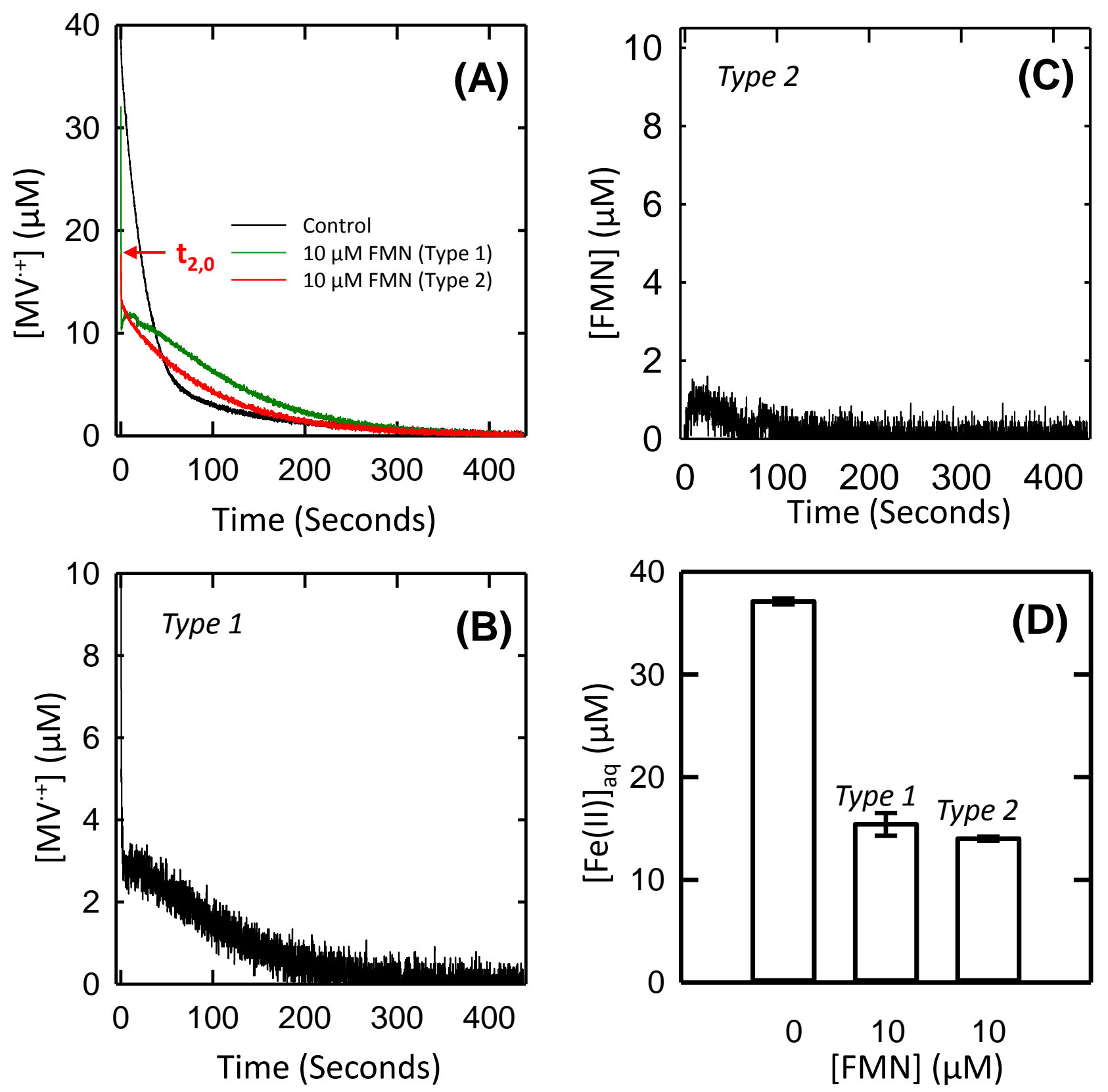

vang et al Figure 3 

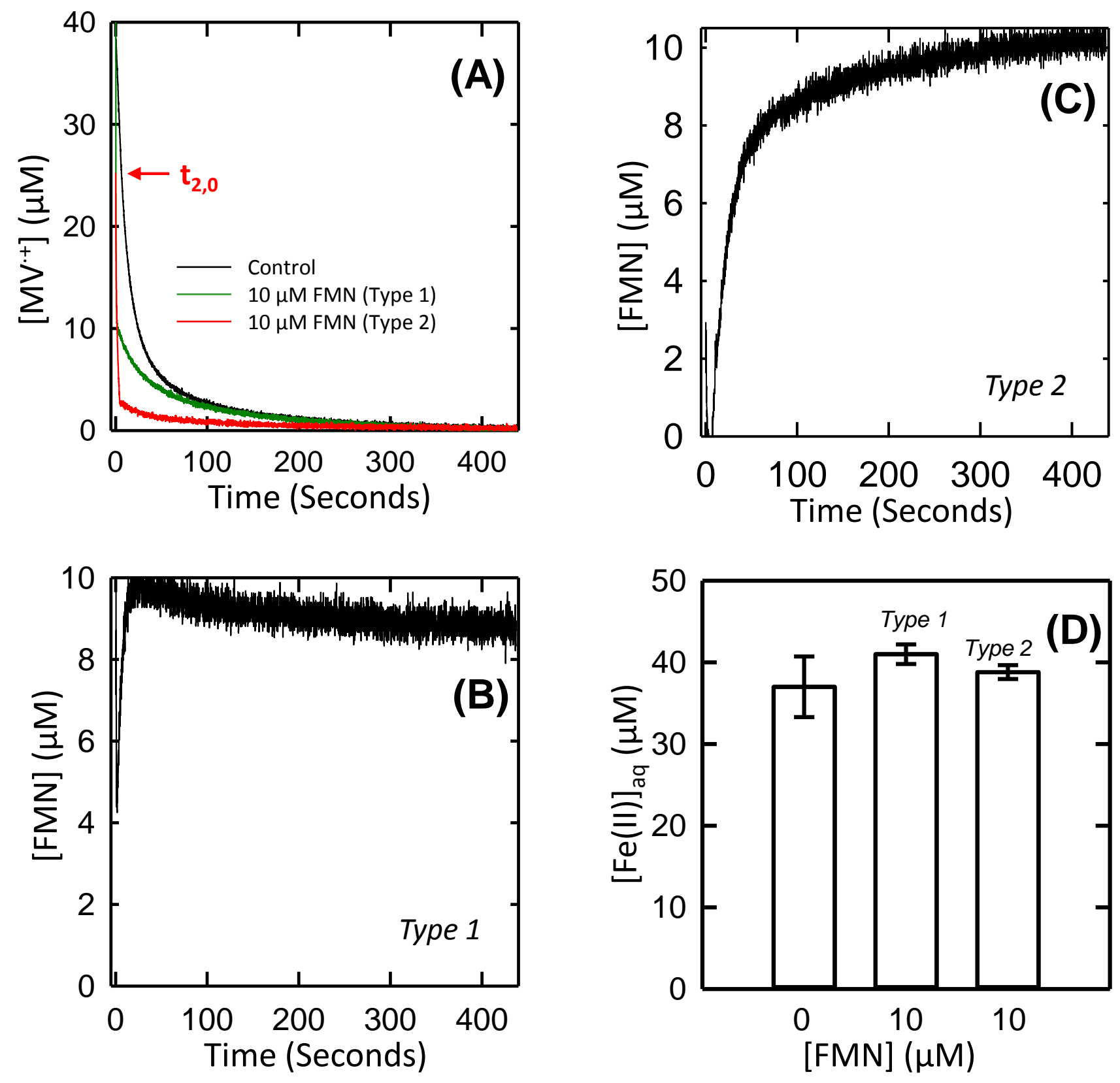

vang et al Figure 4 
MELs + FMN + Fe (III) oxides

FMN $<$ MV, Fe (III) oxide in excess

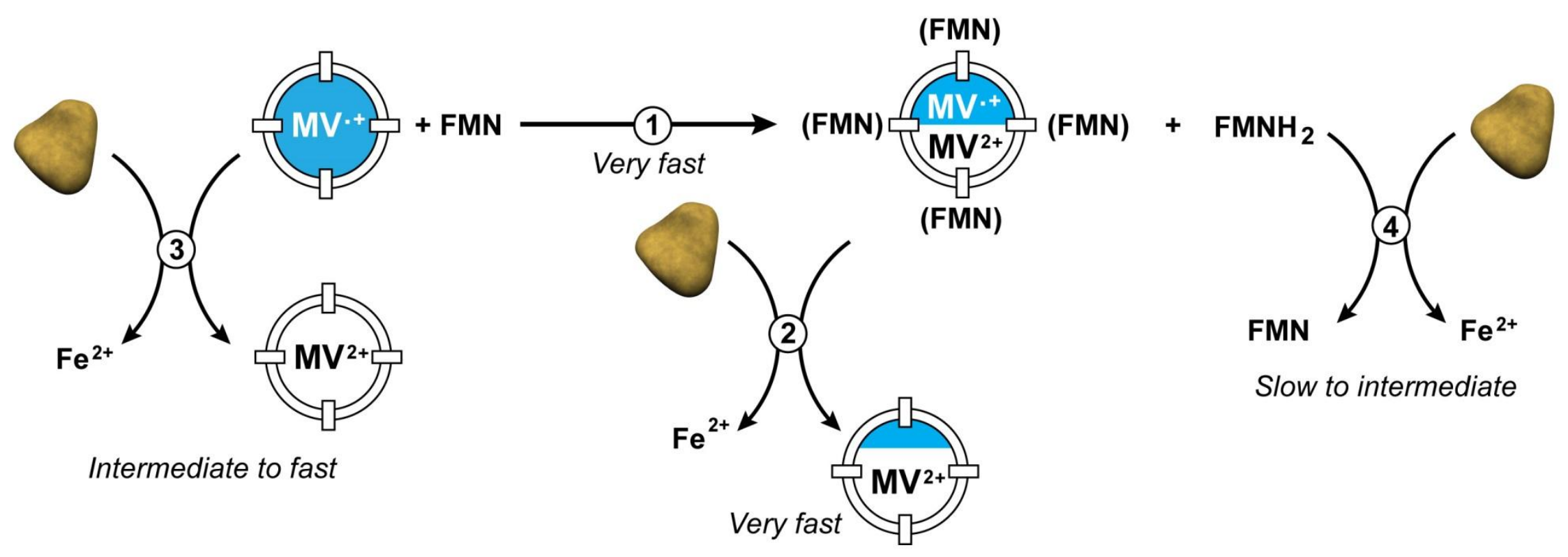

Wang et al Figure 5 


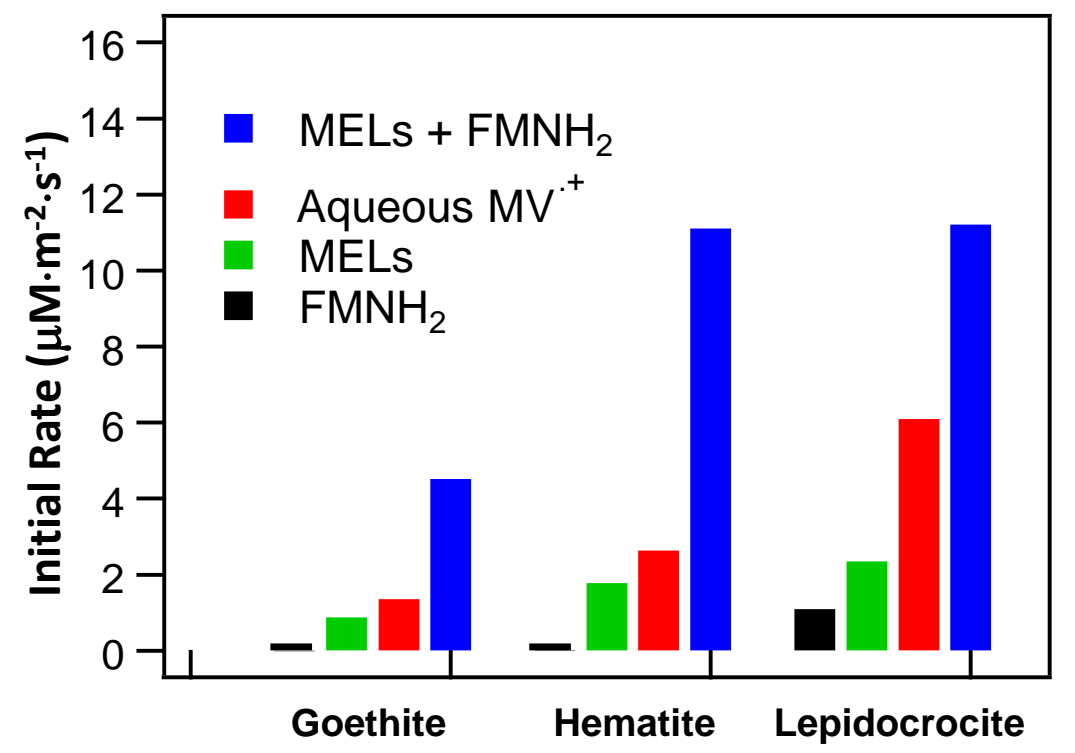

Wang et al Figure 6 